\title{
Personal storytelling in mental health recovery.
}

\author{
Dr Kate Nurser \\ Cambridgeshire and Peterborough NHS Foundation Trust, UK \\ Email address for correspondence: katenurser912@gmail.com \\ Dr Imogen Rushworth \\ Department of Clinical Psychology, University of East Anglia, UK \\ Professor Tom Shakespeare \\ Norwich Medical School, University of East Anglia, UK \\ Dr Deirdre Williams \\ Norfolk and Suffolk NHS Foundation Trust, UK
}

\begin{abstract}
Purpose: Creating more positive individual narratives around illness and identity is at the heart of the mental health care recovery movement. Some recovery services explicitly use personal storytelling as an intervention. This paper looks at individual experiences of a personal storytelling intervention, a recovery college Telling My Story course.
\end{abstract}

Design/methodology/approach: Eight participants who had attended the Telling My Story course offered at a UK recovery college were interviewed. Data were analysed using Interpretative Phenomenological Analysis.

Findings: Five key themes emerged: a highly emotional experience, feeling safe to disclose, renewed sense of self, two-way process and a novel opportunity.

Originality/value: The findings suggest that storytelling can be a highly meaningful experience and an important part of the individual's recovery journey. They also begin to identify elements of the storytelling process which might aid recovery, and point to pragmatic setting conditions for storytelling interventions to be helpful. More time could be dedicated to individuals telling their story within UK mental health services, and we can use this insight into the experience of personal storytelling to guide any future developments.

Keywords: Storytelling; mental health recovery; interpretative phenomenological analysis; narrative therapy.

Paper type: Research paper. 


\section{Introduction}

Personal recovery in mental health involves a deeply individual journey of finding meaning in life, beyond the limitations of a mental health problem (Anthony, 1993). The recovery approach moves away from professional-led care and instead empowers individuals to become experts in their own self-care; building on their strengths to re-discover an identity that is separate from illness or disability (Perkins et al., 2012). The key concepts found to be important in personal recovery are conceptualised by the CHIME framework (Leamy et al., 2011): Connectedness, Hope and optimism, Identity, Meaning and purpose, and Empowerment.

An innovation in the UK recovery movement has been the development of recovery colleges, which take an educational approach to addressing mental health difficulties. Individual service users, professionals and carers can attend as students on courses that are coproduced and co-facilitated by those with lived experience of mental health problems (Perkins et al., 2012). Recovery colleges are underpinned by an ethos of experience-sharing and normalising of mental health difficulties, and personal storytelling is at the heart of this. Peer workers aim to instil hope in others by sharing their story; as relatable people who are reconstructing a positive self-identity despite the challenges of a mental health problem (Repper, 2013). In addition, individuals are encouraged to form their own recovery story and to share this with others (Shepherd et al., 2014).

It is thought that having a self-authored record of what has happened supports the individual to move forwards in their recovery, through making sense of their experiences and feeling heard by others (Scottish Recovery Network, 2012). Some recovery colleges offer specific courses that equip people to tell their own recovery story. Recovery College East (RCE; part of Cambridgeshire and Peterborough NHS Foundation Trust) is one example, offering the Telling My Story (TMS) course that runs for four weekly half-day sessions. The TMS course is novel in that it brings together the forming (sessions 1-3) and the sharing (session 4) of one's recovery story, supporting individuals to make sense of what has happened to them and celebrate who they are, with others. Peer support tutors facilitate the course and it can be attended by service users, carers and Trust staff members. Typically, four to eight people attend per cohort.

Given that TMS has grown somewhat organically, formal research and evaluation data are lacking, as it is elsewhere in other recovery settings (Shepherd et al., 2014). The course is highly valued by students and staff, but reports of how storytelling impacts on students is limited to informal feedback. Given the centrality of personal stories to the culture of mental health recovery, it seems vital to know more about the experience of storytelling.

We can look to the wider literature for some insight. Telling personal stories is recognised as a fundamental aspect of human experience (Plummer, 1995). We unremittingly interpret and 
re-interpret our experiences; constructing a way of telling about ourselves that is inextricably bound with our personal and social identity (Bruner, 1987). The presence of a mental health problem has the potential to put one's life story - and indeed, one's identity - into disarray. It is suggested that storytelling allows us to regain a sense of order by making links between our sense of self, temporality, social standing and morality (Crossley, 2000).

Constructing a narrative has shown to impact positively on both physical and mental wellbeing (Pennebaker and Seagal, 1999) and the disclosure of distressing information can have cathartic benefits (Frattaroli, 2006). We see narrative interventions used widely in mental health; from narrative exposure for trauma (Schauer et al., 2011), through to narrative therapy (White and Epston, 1990). Typically, however, these approaches focus on forming the story at a private level, whereas storytelling involves sharing the story on a public platform and therefore exposes the self to social shaping by the responses of others (McLean et al., 2007).

There is some preliminary evidence to suggest that interventions incorporating storytelling are helpful in reducing symptoms and increasing functioning (Gunnarsson and Eklund, 2009; Roe et al., 2014; Russinova et al., 2014). However, the lack of qualitative literature exploring the individual's experience of these interventions means that attempts to capture outcomes are being made without clarity around which domains to measure. Preliminary findings about service user experiences of two specific storytelling interventions are available. Roe et al. (2010) found that group storytelling led participants to experience a reformation of self through narrative change; facilitated by an accepting environment and taking an active role through narration. Amongst the themes were ideas of connection to others, emotional change from opening up, and increased hope from seeing others' achievements. Gunnarsson et al. (2010) reported that one-to-one storytelling with a professional helped participants to develop a sense of coherence and facilitated emotional catharsis, whilst the practical task of forming a story helped to develop agency.

The qualitative findings outlined above offer some insight into the experience of storytelling, but are limited in transferability since the studies took place in Israel and Sweden with specific interventions. In addition, such findings appear to align to the recovery movement's positive ideology and whilst this may represent the experience of those using the interventions, it is important to remain open to alternative perspectives on recovery. For example, we are alerted to the potential for recovery to become "mainstreamed" (Rose, 2014) whereby the process of normalising recovery could facilitate the emergence of a dominant recovery narrative and the subsequent silencing of stories that do not conform to what recovery should look like (Morgan et al., 2016). 
What is needed is inductive exploration of the experience of storytelling in a UK mental health recovery context, to allow the perspectives of those using storytelling to emerge freely. The TMS course offered at RCE provides an opportunity for such research. It is hoped that this paper will increase our understanding of how the storytelling process is experienced by and impacts on those who use it, in order to inform service development and future research and evaluation.

\section{Method}

\section{Study Design}

The study used in-depth interviews with participants who had completed the TMS course at RCE. Ethical approval was obtained through the North West - Liverpool Central Ethics Committee (REC 16/NW/0148). The initial proposal underwent review by the local NHS service user panel.

The study draws on the Interpretative Phenomenological Analysis (IPA) framework; chosen because it is particularly suited to health and social research that aims to explore how individuals make sense of their world, to gather valuable insight that can inform clinical practice (Smith and Eatough, 2007).

\section{Participant Recruitment}

A total of eight participants were recruited (demographic details are outlined in Table 1). Two others were approached within the recruitment process: one did not respond and the other chose not to take part. All eight met the inclusion criteria. Written consent was obtained for each participant on the day of interview, following discussion with the first author to confirm eligibility/capacity to consent, and prior to any discussions taking place.

The inclusion criteria were:

- people aged 18 or over, with a recognised mental health difficulty for which they had received support from secondary mental health services

- people who had completed the TMS course within the last year.

The following exclusion criteria were applied:

- people who were not fluent in speaking and understanding English

- people who lacked the capacity to consent, lacked the cognitive ability to take part, or were functionally impaired to the extent of being unable to take part

- carers and staff members who attended the course.

\section{Data Collection}

Semi-structured interviews were conducted by the first author (KN). The interview guide was developed collaboratively via focus group discussion with recovery college students who 
were not recruited to the study. This is fitting with the recovery model's emphasis on coproduction within the design of research and evaluation projects (Corrigan, 2014). Particular consideration was given to facilitating an interview environment whereby participants felt able to express both positive and negative aspects of the storytelling process.

All interviews were audio-recorded and later transcribed verbatim by $\mathrm{KN}$. Ethical considerations were prioritised throughout the interview, including checking for ongoing verbal consent and debriefing as appropriate.

Table 1

Participant demographic details

\begin{tabular}{|c|c|c|c|c|}
\hline Participant ${ }^{1}$ & Age & Gender & Ethnicity & $\begin{array}{l}\text { Length of time } \\
\text { involved with } \mathrm{RCE}\end{array}$ \\
\hline Sarah & 35 & $\mathrm{~F}$ & White British & 1 year \\
\hline Paul & 71 & $M$ & White British & 2 years \\
\hline Mark & 58 & M & White British & 6 months \\
\hline Brad & 46 & M & White British & 1 year 7 months \\
\hline Janey & 50 & $\mathrm{~F}$ & White British & 3 years \\
\hline Lisa & 29 & $\mathrm{~F}$ & White British & 2 years \\
\hline George & 58 & M & Mixed British \& Asian & 1 year 4 months \\
\hline Judy & 63 & $\mathrm{~F}$ & White British & 6 months \\
\hline
\end{tabular}

\section{Analysis}

Interview data were analysed following guidance on the conduct of IPA (Smith et al., 2009). By an iterative and immersive process, a list of codes was produced for each transcript, then clustered into superordinate themes for that particular participant. After this idiographic stage of analysis (Smith and Eatough, 2007) superordinate themes were developed for the group as a whole, which captured similarities and differences in participants' individual experiences.

\section{Validity and Rigour}

Analysis was primarily undertaken by $\mathrm{KN}$ and aligns to IPA's hermeneutic underpinning, offering this particular researcher's interpretation of how the participant was making sense of their experiences, at that particular time (Smith et al., 2009). A number of steps were used to increase transparency, rigour and trustworthiness of the data including keeping a reflective journal (which also documented all a priori and post hoc analysis decisions), a second focus group with another group of recovery college students (for participant-group feedback on the 
initial analysis), and joint coding sessions with supervisors (to retain fidelity to IPA's epistemological stance and methods).

\section{Results}

Five superordinate themes were identified. Throughout the analytic process, however, the individuality of the storytelling experience was highly evident: each person's story was unique to them, and a reflection of where they were in their recovery at that particular time. The analysis describes each theme in turn. However, the individuality shown across participants is explored within each theme. Table 2 provides an example outline of how one of the overarching themes (theme one) was contributed to by themes within each individual's narrative.

Table 2

Theme 1: A highly emotional experience

\begin{tabular}{|c|c|c|}
\hline \multicolumn{3}{|c|}{ Catharsis and liberation of emotion } \\
\hline Brad & "l'd had a certain level of weight lifted from my shoulders" & P5 \\
\hline Mark & "It's a release" & P32 \\
\hline Janey & $\begin{array}{l}\text { "...It's made me feel like l'm free...l'd written my yoyo life, because how I felt } \\
\text { my life had been was all ups and downs" }\end{array}$ & $\mathrm{P} 12$ \\
\hline Lisa & "It was the first time I really got it all out" & P3 \\
\hline George & $\begin{array}{l}\text { "It's quite revealing....but by keeping it all inside, it just festers and becomes } \\
\text { toxic... once you start to release it, you know, and to come to terms with it, } \\
\text { your mental health obviously improves" }\end{array}$ & P13 \\
\hline \multicolumn{3}{|c|}{ Emotionally demanding } \\
\hline Sarah & "....it was really, really emotional...but it's really stood out for me" & $\mathrm{P} 17$ \\
\hline Paul & "I found it very overwhelming" & P3 \\
\hline Janey & $\begin{array}{l}\text { "I'd had a run-through the night before by myself in the kitchen, and I hadn't } \\
\text { been able to get through telling it without crying, without breaking down in to } \\
\text { tears" }\end{array}$ & P6 \\
\hline Lisa & "...it's quite- quite strong sharing that amount of emotional baggage" & P16 \\
\hline Judy & $\begin{array}{l}\text { "...she [my sister] was a bit worried about me doing it, in case it started } \\
\text { things off again" }\end{array}$ & P8 \\
\hline \multicolumn{3}{|c|}{ Coping strategies } \\
\hline Brad & $\begin{array}{l}\text { "... where it's got the hardest parts, having a little bit of something to laugh } \\
\text { about after that just sort of eases it, releases the tension" }\end{array}$ & $\mathrm{P} 13$ \\
\hline Janey & ..."it made me frame it in a positive light...it's a way of breaking the tension" & P27 \\
\hline George & $\begin{array}{l}\text { "You could actually weave in the good things with the negative things...the } \\
\text { process is good because I can balance telling my story....it's not all doom } \\
\text { and gloom, you know" }\end{array}$ & P31 \\
\hline
\end{tabular}

\section{Theme One: A Highly Emotional Experience}

Storytelling was experienced as emotionally charged in both helpful and challenging ways. A number of participants described a sense of catharsis achieved from "getting it all out", contrasted to keeping things inside whereby "it just festers and becomes toxic" (George). 
There was a strong sense of liberation from being able to express previously hidden parts of self.

Brad: "Well I'd had a certain level of weight lifted from my shoulders. It's- I got the full story I wanted to tell off- off my chest, so it- it had- it's actually helped lighten melighten my mood a great deal."

Lisa described expressing her difficult early experiences that she had previously kept hidden. This was a significant step along her recovery journey:

Lisa: "It was the first time I really got it all out [...] I-I still need to go back and have some therapy on some stuff from when I was a kid, to learn to deal with it, but I'm much more stable now to do that, and [pause] telling my story was a big part of that because it let me tell people what had gone on with my childhood."

Storytelling enabled participants to externalise difficult internal experiences, such that their emotional impact became more manageable. Lisa did this through song, and another participant used a yoyo to give physical presence to the emotional ups and downs that she was experiencing on the inside, with a hopeful message that she would always "bounce back up". Most participants stressed, however, that the benefits of storytelling were coupled with it being a highly demanding emotional experience. Sarah described an initial catharsis, coupled with high anxiety when telling her story and exposing herself, followed by positive feelings upon reflection once the intense emotion had reduced.

Exploring the more difficult parts of self (those often repressed, or avoided) stirred up a lot of difficult feelings, and some participants feared that this would exacerbate dwelling on negatives. For some, it was important to include humour in their story to counterbalance the difficult aspects and "release the tension" (Brad); both for themselves, and the listener. Some participants spoke about using positivity to cope with the emotional demands of storytelling.

Janey: "I felt a lot more positive about my story because it- it made me frame it in a positive light. This course made me like- like it was a requirement to frame it positively, which I- is something I find very difficult."

As noted by Janey's description ("This course made me"), positive reframing is somewhat imposed by the course structure. However, participants valued this and reported that including positive elements to their story became essential to their recovery. 


\section{Theme Two: Feeling Safe to Disclose}

All participants made reference to the idea of safety and how this impacted on their level of disclosure. Within the course environment, participants gained comfort in knowing that other students would be understanding of their difficulties.

Mark: "It allows you to share things totally, without fear, without thinking that anyone's going to think badly of you, and that they're all on your side."

Words such as "warm" (Sarah, Brad, Lisa), "supportive" (George) and "nurturing" (Janey) were amongst descriptions of the TMS environment. For many, this was their first experience of feeling safe enough to tell their story. This was frequently compared to other environments, whereby it felt unsafe to disclose and fear of negative judgment prevailed. Some referred to experiences of stigmatisation in social and personal arenas (Mark, Janey), and the majority of participants spoke about keeping their story from those closest to them. For some, this was due to fear of upsetting those who may be closely tied to the story (Paul, Brad, Lisa). Others described family context that did not support open sharing and emotional connection (Mark, Brad) and for George this was linked to his cultural background where mental health issues were not discussed openly.

In contrast, the TMS course was experienced as a place where others were "willing to listen" (George) and individuals were "given time" (Sarah). Participants referred to a deeper level of connection achieved through mutual sharing, at times in contrast to relationships outside of the course:

Janey: "You don't really go into deep meaningful conversation with somebody [laughs] as you would- as you would do on the course. So, you know, you kind of really felt you had a connection with some- you know, with people on the course."

For one participant, however, the course environment was not such a safe space. Paul described his storytelling experience as "overwhelming" because he felt that he was shocking others, and he experienced others as disbelieving. Paul described a history of not being believed in relation to his psychotic experiences, which may have contributed to a feeling of not being believed by other students, and left him feeling emotionally uncontained (linking to theme one). As a result, he regretted his disclosure and did not anticipate sharing his story beyond the course.

\section{Theme 3: Renewed Sense of Self}


For all participants, telling their story seemed to lead to some kind of discovery (or rediscovery) about themselves, which acted as a catalyst for starting to overcome their suffering. The story format prompted participants to acknowledge past difficulties, and give them some kind of order. Sarah told her story chronologically, in a storybook format with photo images.

Sarah: "I just feel like it's, like, organised my brain a bit more."

This allowed for sense-making and for new understandings to develop (for example, linking early experiences to later life challenges). A number of participants felt their story provided some kind of grounding or waymark; a reference point for future sense-making and development of self.

Brad: "Hopefully it's going to be something I can look at, and identify where l've moved forward, as I- as I carry on through it's something I'll look back on and say okay yeah, I've- I recognise I was feeling like that but now I can see that I'm feeling much more relaxed with different things."

Brad's ability to "recognise I was feeling like that" was significant within the wider context of his interview. Telling his whole story allowed him to acknowledge the difficult times he'd had, which facilitated understanding of what was keeping him stuck, such that he could make positive changes and re-engage with his values. One such value was writing; after writing his story on the course he set up an online blog, through which he continued to tell his story and re-integrate himself with others.

Re-integration and increased engagement was reported by many. For George, whose feelings of not being worthy had led him to social isolation and depression, the experience of being heard and validated had begun to open up opportunities for re-engaging in the social world:

George: "I've always been a loner. Yeah l'd sit at home and eat takeaways and watch YouTube videos. Very sad, you know. I don't have much of a life at all really, because I don't feel like- I have no right to say anything. Well I haven't had a right to say anything, and I- I'm starting to see how a social life works, you know. Taking an interest in- in [short pause] the theatre, or you know, music."

Having attended the course for the second time, George described how he was gradually learning more about himself, and expressed a desire to attend the course again in future to continue this process. Across all participants' experiences, there was a sense that stories aren't static. Rather, they evolve over time according to the individual's stage of recovery. Lisa had subsequently shared her story on a different recovery college course, and reflected on how her relationship to her story changed over time. 
Lisa: "I was stronger. I was more connected to myself [... I'm more able to connect and feel- excuse me- and feel [short pause] almost sad for myself, and empathise, and connect with that [...] So I can now think [short pause] some of that was- well my stuff as a kid wasn't my fault, but some of my decisions I made as an adult were my fault, but I can forgive myself for that, and I can move forwards."

Becoming more emotionally connected has allowed Lisa to be more compassionate towards herself, empathising with the things that have happened out of her control, and taking responsibility for the things that she can influence moving forwards. Acknowledging and accepting the more problematic parts of self was reported by many as instrumental in allowing them to progress in their recovery.

Two participants benefited from organising their story, but had difficulty reflecting on how storytelling had impacted on their sense of self. For Judy, it was particularly important to have developed a new perspective regarding her psychotic symptoms, but there was a feeling of emptiness within the interview when prompted for further reflection on what this meant to her. A reflective journal entry, made following the interview, reads:

"She was speaking in quite a detached way. My interpretation was that forming her story had helped her to organise experiences, but there wasn't much emotion or meaning there; it was reporting of facts. I feel quite sad for her, but I'm wondering how much of this is me needing to adjust my expectations of how storytelling "should" impact on somebody, to be most beneficial. For me, just noting the key events wouldn't have helped much; I'd need to go further than this. Perhaps for Judy and her stage of recovery, however, this organising of experiences was enough to have a positive impact and help her regain a sense of control over what's happened." (Reflective Journal, 30.09.16)

It was important for $\mathrm{KN}$ to bracket her own preconceptions (Smith et al., 2009) and enter Judy's world to understand the personal context of her storytelling experience. This led KN to a new understanding of how storytelling can impact people on different levels, according to their stage of recovery and what they need or are ready for at that time.

\section{Theme Four: A Two-Way Process}

Participants valued the opportunity to experience both the teller and the listener role. As tellers, participants received feedback from the listeners, which often shaped how they felt about themselves and their story. This was hugely significant for Lisa, whose past attempts to disclose childhood abuse had been met with disbelief and rejection.

Lisa: "The first time I saw the reaction on people's faces at what I was saying, was the first time l'd really felt [short pause] any empathy." 
Receiving empathy from others allowed Lisa to begin to accept the hidden parts of herself, which in turn allowed her to become more emotionally connected (theme three). A number of participants said they regularly revisited their feedback cards (completed by group peers after an individual had told their story) and felt warmed by the positive comments received.

Telling your story also provides an opportunity to impact upon the listener. Many participants hoped that their story could provide support to others. Janey had previously told her story in a counselling context, which she found emotionally draining and quite unhelpful. Her storytelling on the course had a different focus:

Janey: "Instead of like me just telling it for me, it was more looking at it in the pointfrom the point of view of how it could help other people that are listening to me tell my story $[\ldots]$ In telling it in a way that will inspire others, you're also telling it in a way that will inspire yourself."

For Janey, telling her story in a way that would inspire others, had the added benefit of enabling her to feel inspired herself. Other participants felt that they would be more likely to share their story in future if they perceived it would benefit the listener.

When in the listener position, participants described feeling inspired by other people's progress in spite of adversity, particularly if they could relate to the teller in terms of similarities in experiences. There was a sense of "if they can do it, I can", felt by many and described here by George:

George: "Other people here sort of gave me the confidence to- knowing that they have had difficulties, you know, that they have started to [short pause] through the recovery process have started to try see their lives in different ways. It gave me the confidence to think well I can do the same, you know."

George identified as a "loner" and described "stuckness" when he first told his story as he struggled for hope and motivation. It wasn't until hearing stories from others whom he could relate to about successfully making changes that he felt compelled and confident to do the same for himself.

Another important aspect of the listener role was offering feedback to other tellers.

Lisa: "It meant a lot. It meant that I could show them that I had listened, and that I did care."

Although giving positive comments was encouraged by the course format, there was a genuine sense across all participants of wanting to reciprocate meaningful feedback to others. Many people commented that feeling that they were helping others fostered feeling good about themselves. 
The process of self to other comparison was described in some way by all eight participants. For most, this seemed a positive experience; resulting in either favourable self-other comparison ("it made me think I was doing quite well" - Judy, others were "worse off" Mark), or at least a reaffirmation that they aren't alone in the challenges they face. For Paul, however, the self-other comparison was unfavourable. When asked whether anything would have made the storytelling process more useful to him, he replied:

Paul: "If other people had been in the same situation, had been abused, along those lines, then I could have said yes I've been, and I wouldn't have felt so out of place, but it seems a lot of them were just, what l'd say, got little niggles. [laughs] They're [pause] on the scale of one to ten they are probably about a two or a three, while I'm up at eight or nine."

The storytelling process seemed to reinforce feelings of isolation that Paul experienced in his wider life. He perceived himself to be "worse-off" than others, which perhaps left him in a cutoff position. Subsequently, he held back from full disclosure of his psychotic experiences and past abuse within his story. Linking to theme two, Paul did not experience connection to others or feel safe enough to disclose fully, so he did not have the same positive experience of being a teller or a listener that other participants described.

\section{Theme Five: A Novel Opportunity}

This theme outlines participants' descriptions of storytelling as something novel, rather than an everyday act. This was seen in the language used to describe the experience, for example: "performance"/ "on the stage" (Janey) and "audience" (Brad). Participants reported a degree of planning, as sharing their story was not something they would just go and do. This is perhaps partly due to the TMS course format of three preparation sessions, leading up to the sharing session. For some, sharing their story on the course led them to feel that future sharing was possible, but many felt unsure about whether, or in what context, they might feel compelled to share their story beyond the course. This seemed to link to feelings of safety within the course environment, which participants felt they could not guarantee in other environments (theme two).

The novelty of storytelling on TMS appears to offer both benefits and drawbacks. Participants valued the opportunity for reflection, described by Mark as "standing outside of myself". This seemed to allow individuals to engage in sense-making and gaining new perspectives, as seen in theme three. Others were particularly appreciative of being given the time and freedom to tell their story how they wanted to.

Sarah: "I just think it gives some- you a chance to have your own voice. It gives an opportunity to maybe say once and for all what your whole story is, rather than tell 
bits here and there to different people. It's like you're kind of coming together as one and saying "right, this is it."

For Sarah, the protected time to have her "own voice" and tell her "whole story" was hugely significant to her recovery. She suffers with high anxiety and often struggled to articulate herself within the interview. In the excerpt above, however, she demonstrated greater assertion (fluent speech, emphasis on "this"), indicating that she had indeed "found her voice". Sarah told her story through photography, which provided physical embodiment of a more difficult time that is no longer obvious, but that she does not want to simply forget.

The sense of "wholeness" referred to by Sarah was mentioned by a number of participants, and often contrasted with time-pressured clinical environments where individuals might have told some of their story, but with partial details or where the telling was constrained by a professional agenda.

Brad: "I think with a counselling session, there's a lot- I have a lot less focus for myself because it's more led by the questions of the counsellors, and I- so I [short pause] I- I feel less able to tell it in the way that I want to- want to tell it and so I- I can't always exp- tell the- the entire story that I might want to tell."

Brad had not felt able to express his complete story until attending the TMS course, which had meant he felt he had never quite understood himself or felt understood by professionals. This is in the context of experiencing high social anxiety, and the excerpt above shows some difficulty articulating himself within the interview (indicated with stuttering, hesitation, pauses; and body language observed at interview). It seemed highly important for participants to have choice and freedom in how they told their story, so that it could be a true reflection of who they are.

The drawbacks to storytelling being a novel activity centred on it being anxiety-provoking and challenging, particularly for those who suffered with elevated anxiety as part of their mental health difficulty. We saw within theme one that storytelling can be a highly emotional experience, and some described how the act of sharing made them feel "scared" (George), gave them "stage-fright" (Janey), or created pressure to tell a good story.

\section{Discussion}

The findings provide some empirical evidence to support the popular notion that storytelling may have an important role to play in personal recovery (Scottish Research Network, 2012; Shepherd et al., 2014). This is evident in how the themes link to the CHIME framework (Leamy et al., 2012): mutual sharing through storytelling allowed for connectedness to others (themes two and four); feeling inspired by others' stories led to increased hope (theme four); individuals gained a renewed sense of identity from connecting with their emotions and experiences through telling their story (themes one and three); reflection and making sense 
of experiences allowed for new meaning and reconnecting to values (themes three and five); and taking an active role through telling one's story provided empowerment and greater confidence to re-engage in life (themes three and five). TMS was in general highly valued by participants, but it has to be considered that perhaps those students with more negative experiences would not have come forward to participate.

The findings expand upon Bruner's (1987) notion that storytelling is inextricably linked to both personal and social identity. At the individual level, storytelling can have a profound impact in terms of emotional catharsis (theme one) and identity reformation (theme three), and the story itself can be a form of self-expression (theme five). However, the telling in storytelling makes it a social act; and themes two and four show that the role of other people is central to the storytelling experience.

These findings support ideas that storytelling helps to develop a sense of coherence (Gunnarsson et al., 2010) and facilitates some kind of reformation of self (Roe et al., 2010). Engaging with TMS required individuals to adopt a new way of telling about themselves, following the story format and drawing out positives. Plummer (1995) identifies common structural components that tend to feature within the stories we tell (a sense of journey, some form of suffering, and then triumphing over adversity), and particularly in survivor narratives seen across many minority groups. Plummer highlights how "stories breed stories" because one person speaking out against the dominant narrative (in this case, stigmatising discourse around mental health) enables others to also "come out", such that negative experiences are transformed into stories of survival and overcoming adversity. The findings suggest that the stories participants told about themselves may have been shaped by the narrative demands of the course, which facilitated: the expression and documentation of suffering that may have previously remained hidden (themes one and five), organising of experiences in a logical format that allowed for new perspectives to emerge (theme three), and the inclusion of hopeful or triumphant elements in order to inspire others (theme four). For most, this new way of telling about oneself (theme three) facilitated a more positive selfidentity (Bruner, 1987).

Theme five highlights the importance of having protected time, allowing the individual to tell their whole story exactly how they want. The practical task of forming and sharing one's story led to increased agency, as reported elsewhere (Gunnarsson et al, 2010; Roe et al., 2010), and seems to facilitate engagement in wider life; particularly when coupled with reconnection with personal values and increased hope about being able to live by these (themes three and four). Agency is considered an important factor for recovery (Davidson, 2003) and emphasises empowering individuals to become experts in their own self-care (Perkins et al., 2012). Storytelling appears to act as a catalyst for this change in dynamic because it is reliant on the individual taking the lead. Perhaps this is an argument for other 
therapeutic approaches to begin with structured personal storytelling, to foster empowerment for the individual from the start.

This research highlights how feeling safe facilitates richer disclosure, whereas feeling unsafe acts as barrier (theme two). The (often novel) opportunity for acceptance and validation from others was highly valued, with many participants internalising the positive feedback of others, such that they came to hold these more positive beliefs about themselves. This could counteract any self-stigma about mental health problems, if the individual has internalised any negative and stigmatising views of others (Roe et al., 2010).

The mutuality of storytelling within this group context fostered feelings of connection and belonging (Maslow, 1943), but also provided an opportunity for individuals to reciprocate their positive experience of storytelling through being both a validating listener and an inspiring teller. This perhaps contributes to increased agency by bringing the individual out of the patient role and into thinking about others, and it is well documented that altruistic acts can foster feeling good about oneself (Post, 2005). Shepherd et al. (2008) state that "finding you have something to give, as well as needing help is central to building a positive sense of self-esteem and this is at the heart of recovery" (p. 5). Perhaps storytelling can help facilitate this.

The group processes involved in storytelling and seen in this study support the welldocumented notion within recovery that hearing other people's stories can inspire hope (Repper, 2013). Seeing a peer progress with their recovery despite adversity may challenge the individual's perception of what it means to have a mental health problem, inspiring an attitude of "if they can do it, I can" so that having a mental health problem is no longer as limiting.

Across the themes, we can see how the process of storytelling can impact upon the individual's wider sense of self and how they position themselves in the social world. Having a mental health problem can lead to a sense of "spoiled identity" due to feeling socially "abnormal" (Goffman, 1963). The self-stigma that this can create is thought to lead to low self-esteem, low self-efficacy and reduced self-worth (Corrigan and Rao, 2012), with the emotional core of shame (Luoma and Platt, 2015). The findings of this study show that storytelling can offer a platform for experiencing meaningful connection, acceptance and validation from others, which can normalise experiences that might have previously been considered shameful. According to shame resilience theory (Brown, 2006) it is this empathic relational response that allows an individual to overcome shame; because feelings of unworthiness or inadequacy are replaced with a sense of acceptance and belonging, which provides the basis for re-engagement through regaining power and freedom over one's life. 
Shame is now a recognised core component that is common to a broad range of mental health difficulties (Gilbert, 2009), and a construct that perhaps needs greater consideration within the organisation and delivery of mental health services (Leeming and Boyle, 2013). Perhaps storytelling has an important role to play in this, given that the social experience of telling one's story has shown to provide some of the conditions that are understood to be necessary for the alleviation of shame (Brown, 2006).

We are reminded in the case of Paul, however, that non-identification with the group can leave the individual feeling more isolated; rather than accepted, validated or inspired. Thus, feelings of shame may be maintained or even exaggerated. This raises the question of whether the group format of storytelling is appropriate for all, or whether the individual needs to have reached a certain point in their recovery journey prior to telling their story. This is perhaps an area for further investigation.

It is also important to consider the findings in relation to notion that recovery, as a concept, is becoming mainstreamed (Rose, 2014) and could result in individuals feeling coerced in to conforming to the dominant recovery narrative (Morgan et al., 2016). Theme one identifies how participants generally valued the inclusion of positive elements to their story, but by its very nature the course encourages individuals to draw out the positives and therefore imposes a structure to some degree. This raises the question of whether individuals feel able to challenge the more dominant recovery narrative within their own story, or whether they feel coerced in to telling inspiring stories of recovery. It is possible that Paul, for example, had a more negative experience because he felt his story did not align to what a recovery story should look like. Perhaps others who chose not to take part in the research would have liked to tell their story, but did not feel able to tell it in a recovery-oriented fashion. We must therefore embrace and learn from alternative perspectives such as Paul's, to consider how we remain open to and inclusive of all individual experiences of recovery.

\section{Limitations}

We have only heard from those who wanted to speak about their storytelling experience; it could be that those who declined to participate or give consent to being contacted had a more negative experience, or perhaps felt that their story did not fit with the more dominant recovery narrative as discussed above.

In addition, the participants had varying degrees of prior storytelling experience, and were at varying stages of recovery. The IPA methodology allowed for reflection on each individual's context, but we are mindful that this variation makes it difficult to assume transferability of results. Similarly, the lack of cultural diversity within the sample limits the transferability of findings to those from other ethnic backgrounds. 
Fitting with IPA, the results presented offer an interpretation from the perspective of one researcher, without making claim to any absolute truth about the experience of storytelling for all. Although steps were taken to maximise quality and rigour, and increase trustworthiness, the bulk of the analysis was carried out by one researcher $(\mathrm{KN})$ and other studies have benefited from taking a team approach to analysis, to include multiple perspectives.

\section{Implications for Practice}

It is argued that personal stories should have a central place in mental health support, given that their content can preserve individuality within our evidence-based world (Roberts, 2000). The findings of this study complement this notion, by suggesting how meaningful the process of constructing and sharing a recovery story can also be for individuals. More time could be dedicated to personal storytelling within clinical interventions in the UK, in order to empower agency in the client, dedicate time to free expression of the whole story, and aid therapeutic engagement, within a safe and containing setting for disclosure. It will be important to consider, however, how we remain open to accepting a wide range of narrative types and not only those that fit with the more dominant 'recovery narrative' (Morgan et al., 2016). This may have implications for the structure and format of storytelling interventions.

Future research could explore the factors that impact on an individual's readiness to tell their story, and factors that might influence how storytelling is experienced, to guide the future development of storytelling interventions across other contexts. Further research is needed to explore other potential formats of storytelling (one-to-one, for example), given that the group environment was shown to have unhelpful elements for one person.

\section{Acknowledgements}

Supervision: Dr Deirdre Williams, Dr Imogen Rushworth, Professor Tom Shakespeare. Consultation on design and organisational support: Tracey Bartlett, Daniel Bowyer. Thank you to the staff and students at RCE who have offered their time and enthusiasm to this project.

\section{Endnotes}

${ }^{1}$ Pseudonyms have been used throughout when referring to participants, to protect their confidentiality. 


\section{References}

Anthony, W.A. (1993), "Recovery from mental illness: the guiding vision of the mental health system in the 1990s", Psychosocial Rehabilitation Journal, Vol. 16 No. 4, pp. 11-23.

Brown, B. (2006), "Shame resilience theory: a grounded theory study on women and shame", Families in Society, Vol. 87 No. 1, pp. 43-52.

Bruner, J. (1987), "Life as narrative”, Social Research, Vol. 54 No. 1, pp. 11-22.

Corrigan. P.W. (2014), "Listen to these lessons", Canadian Journal of Psychiatry, Vol. 59 No. 1, pp. 6-7.

Corrigan, P.W. and Rao, D. (2012), "On the self-stigma of mental illness: stages, disclosure, and strategies for change", Canadian Journal of Psychiatry, Vol. 57 No. 8, pp. 464469.

Crossley, M.L. (2000), "Narrative psychology, trauma and the study of self/identity", Theory and psychology, Vol. 10 No. 4, pp. 527-546.

Davidson, L. (2003), Living Outside Mental Illness: Qualitative Studies of Recovery in Schizophrenia, University Press, New York, NY.

Frattaroli, J. (2006), "Experimental disclosure and its moderators: a meta-analysis", Psychological Bulletin, Vol. 132 No. 6, pp. 823-865.

Gilbert, P. (2009), "Introducing compassion-focused therapy", Advances in Psychiatric Treatment, Vol. 15 No. 3, pp. 199-208.

Goffman, E. (1963), Stigma: notes on the management of spoiled identity, Prentice Hall, Englewood Cliffs, NJ.

Gunnarsson, A.B. and Eklund, M. (2009), "The Tree Theme Method as an intervention in psychosocial occupational therapy: client acceptability and outcomes", Australian Occupational Therapy Journal, Vol. 56, pp. 167-176.

Gunnarsson, A.B., Peterson, K., Leufstadius, C., Jansson, J. and Eklund, M. (2010), "Client perceptions of the Tree Theme Method ${ }^{\mathrm{TM}}$ : a structured intervention based on storytelling and creative activities", Scandinavian Journal of Occupational Therapy, Vol. 17, pp. 200-208. 
Leamy, M., Bird, V., Le Boutillier, C., Williams, J. and Slade, M. (2011), “Conceptual framework for personal recovery in mental health: systematic review and narrative synthesis", British Journal of Psychiatry, Vol. 199 No. 6, pp. 445-452.

Leeming, D. and Boyle, M. (2013), "Shame and using mental health services: connection and validation or alienation and objectification?", In: 8th biennial conference of International Society of Critical Health Psychology, July, 2013, Bradford, UK.

Luoma, J.B. and Platt, M.G. (2015), "Shame, self-criticism, self-stigma, and compassion in acceptance and commitment therapy", Current Opinion in Psychology, Vol. 2, pp. 97101.

Maslow, A. H. (1943), "A theory of human motivation", Psychological Review, Vol. 50 No. 4, pp. 370-396.

McLean, K.C., Pasupathi, M., and Pals, J.L. (2007), "Selves creating stories creating selves: a process model of self-development", Personality and Social Psychology Review, Vol. 11 No. 3, pp. 262-278.

Morgan, A., Felton, A., Fulford, B., Kalathil, J. and Stacey, G. (2016), Values and ethics in mental health: an exploration for practice, Palgrave, London.

Pennebaker, J.W. and Seagal, J.D. (1999), "Forming a story: the health benefits of narrative", Journal of clinical psychology, Vol. 55 No. 10, pp. 1243-1254.

Perkins, R., Repper, J., Rinaldi, M. and Brown, H. (2012), "Recovery Colleges”, Centre for Mental Health, available at: http://www.imroc.org/media/publications/ (accessed 5 January 2017).

Plummer, K. (1995), Telling Sexual Stories: Power, Change and Social Worlds, Routledge, London.

Post, S.G. (2005), "Altruism, happiness and health: it's good to be good", International Journal of Behavioural Medicine, Vol. 12 No. 2, pp. 66-77.

Repper, J. (2013), "Peer support workers: theory and practice”, Centre for Mental Health, available at: http://www.imroc.org/media/publications/ (accessed 5 January 2017). 
Roberts, G. (2000), "Narrative and severe mental illness: what place do stories have in an evidence-based world?" Advances in Psychiatric Treatment, Vol. 6, pp. 432-441.

Roe, D., Hasson-Ohayon, I., Derhi, O., Yanos, P.T. and Lysaker, P.H. (2010), "Talking about life and finding solutions to different hardships: a qualitative study on the impact of narrative enhancement and cognitive therapy on persons with serious mental illness", Journal of Nervous and Mental Disease, Vol. 198 No. 11, pp. 807-812.

Roe, D., Hasson-Ohayon., Mashiach-Eizenberg, M., Derhy, O., Lysaker, P.H. and Yanos, P.T. (2014), "Narrative Enhancement and Cognitive Therapy (NECT): a quasiexperimental study", Journal of Clinical Psychology, Vol. 70 No. 4, pp. 303-312.

Rose, D. (2014), "The mainstreaming of recovery", Journal of Mental Health, Vol. 23 No. 5, pp. 217-218.

Russinova, Z., Rogers, E.S., Gagne, C., Bloch, P., Drake, K.M. and Mueser, K.T. (2014), "A randomized controlled trial of a peer-run Antistigma Photovoice intervention", Psychiatric Services, Vol. 65 No. 2, pp. 242-246.

Scottish Recovery Network. (2012), Reflections on Recovery. Scottish Recovery Network, Glasgow, available at: https://scottishrecovery.net/wpcontent/uploads/2012/05/srn_reflections_on_recovery.pdf_accessed 29 November 2016).

Schauer, M., Neuner, F. and Elbert, T. (2011), Narrative Exposure Therapy: A Short-Term Treatment for Traumatic Stress Disorders, Hogrefe, Cambridge, MA.

Shepherd, G., Boardman, J., Rinaldi, M. and Roberts, G. (2014), "Supporting recovery in mental health services: quality and outcomes", Centre for Mental Health, available at: http://www.imroc.org/media/publications/_(accessed 5 January 2017).

Shepherd, G., Boardman, J. and Slade, M. (2008), Making Recovery a Reality, Sainsbury Centre for Mental Health, London, available at: https://www.centreformentalhealth.org.uk/making-recovery-a-reality (accessed 10 January 2017).

Smith, J.A. and Eatough, V. (2007), "Interpretative phenomenological analysis", in Lyons, E. and Coyle, A. (Eds.), Analysing Qualitative Data in Psychology, Sage, London, pp. 35-50. 
Smith, J.A., Flowers, P. and Larkin, M. (2009), Interpretative Phenomenological Analysis: Theory, Method and Research, Sage, London.

White, M. and Epston, D. (1990), Narrative Means to Therapeutic Ends, W.W.Norton, New York. 